\title{
Avanços na política de mobilidade por bicicleta em Campinas: comparação entre os Planos Diretores de 2006 e de 2018
}

\author{
Advances in the Cycling Mobility Policy in Campinas: Comparison \\ between 2006 and 2018 Master Plans
}

\author{
Pamela Shue Lang Lin ${ }^{1}$ y Ana Maria Girotti Sperandio ${ }^{2}$ \\ Fecha de recepción: 06-02-2020 - Fecha de aceptación: 13-05-2020 \\ Hábitat y Sociedad (ISSN 2173-125X), n. ${ }^{\circ}$ 13, noviembre de 2020, pp. 251-263. \\ http://dx.doi.org/10.12795/HabitatySociedad.2020.i13.14
}

\section{Summary}

The growing use of bicycle as a means of transportation in urban centers points to an alternative to the current means of transportation crisis. The progress of the cycling results in several benefits that continuously attract populations and public institutions to invest in its expansion. However, attention must be paid to the legal consistency of this development process in order to fully ensure the potentials it has to offer.

The study of the evolution of urban documents that determine urban mobility is of great importance to identify the legal advances regarding the cycling mobility policy. In the city of Campinas, Brazil, the comparison between the 2006 and 2018 Master Plans allowed to affirm that there are advances in the political recognition of the cycling as a mean of transportation to be developed.

Other legal documents dealing with the use of bicycle for mobility, however, highlighted the uniquely technical nature of these advances, which revealed the need for an interdisciplinary approach that considers the specificities of this mode and that gives the cyclist proper centrality.

\section{Key words}

Cycling mobility; Legal Advances; Master Plan; Campinas

\section{Resumo}

O crescimento do uso da bicicleta como meio de transporte nos centros urbanos aponta uma alternativa à crise dos meios de deslocamento vigentes. O progresso deste modal resulta em diversos benefícios que atraem continuamente populações e instituições públicas a investir em sua expansão. É necessário, contudo, atentar-se à consistência legal deste processo de desenvolvimento a fim de assegurar plenamente os potenciais que este tem a oferecer.

O estudo da evolução dos documentos urbanísticos que determinam a mobilidade urbana são de grande importância para identificar os avanços legais referentes à política de mobilidade por bicicleta. No município de Campinas, Brasil, a comparação entre o Planos Diretores de 2006 e de 2018 permitiu afirmar que existem avanços no reconhecimento político do modal cicloviário como um meio de transporte a ser desenvolvido.

Outros documentos legais que tratam do uso da bicicleta para a mobilidade, entretanto, evidenciaram o caráter unicamente técnico destes avanços, o que revelou a necessidade de uma abordagem interdisciplinar que considere suas especificidades e que confira a devida centralidade ao ciclista.

\section{Palavras chave}

Mobilidade por bicicleta; Avanços legais; Plano Diretor; Campinas

1 Arquitecta e urbanista. Integrante do grupo de pesquisa em "Estudos e pesquisas de metodologias sobre Planejamento Urbano para Cidades Saudáveis. Professora de la Faculdade de Engenharia Civil, Arquitetura e Urbanismo - Universidade Estadual de Campinas. Av. Albert Einstein, 901, Cidade Universitária, Campinas, SP, Brasil. E-mail: pamelasllin@gmail.com. ORCID: 0000-0002-25750129 .

2 Doutora (2001) em Saúde Pública pela Universidade de São Paulo, USP, com Pós-Doutorado em Saúde Coletiva pela Universidade Estadual de Campinas, UNICAMP (2006). Professora Permanente do Programa de Pós-Graduação em Arquitetura, Tecnologia e Cidade da Faculdade de Engenharia Civil, Arquitetura e Urbanismo - FEC, UNICAMP, e Pesquisadora líder do Grupo de Pesquisa em "Estudos e pesquisas de metodologias sobre Planejamento Urbano para Cidades Saudáveis" do Laboratório de Investigações Urbanas - LABINUR - FEC/UNICAMP. E-mail: amgspera@gmail.com. ORCID: 0000-0002-9373-7727. 


\section{Introdução ${ }^{3}$}

A manutenção de políticas públicas favoráveis ao crescimento do uso de transporte individual motorizado nas cidades brasileiras acarreta diversas externalidades, impactos negativos que influenciam toda a população e não apenas aos proprietários de automóveis. Os malefícios podem ser visualizados tanto na saúde física da população quanto na saúde da cidade: emissão de poluentes, excesso de ruído, sedentarismo, acidentes, barreiras físicas, alto grau de impermeabilização do solo e enchentes decorrentes, desvalorização de atividades próximas a fluxos intensos e tempo desperdiçado em congestionamentos que influenciam na economia de produção são mais que suficientes para evidenciar a necessidade de se repensar a manutenção das políticas públicas voltadas ao setor automobilístico.

A desigualdade social pode ser a pior das externalidades, pois a faixa de renda está diretamente associada às oportunidades de deslocamentos (Instituto de Pesquisa Econômica Aplicada, 2013) e, por consequência, ao acesso a bens e serviços que a cidade venha a oferecer. A mobilidade espacial e urbana, portanto, favorece a mobilidade social à medida que permite o acesso da população a equipamentos urbanos para o seu desenvolvimento (Corrêa, Cunha e Boareto, 2010). O direito de ir e vir expresso na Constituição Federal de 1988 do Brasil (1988) é primordial para possibilitar esse acesso e usufruto dos equipamentos de habitação, educação, trabalho, lazer, cultura, justiça e saúde no país. Considerando que a oferta de tais bens e serviços não é homogênea no território e sim locada por centralidades "a mobilidade urbana é determinante na garantia do direito à cidade" (César, 2010, p. 34), sendo a acessibilidade urbana o retrato da facilidade desse alcance, seja na escala da rua, do bairro ou da cidade (Silva, 2009) e tratar com igual importância os diferentes meios de se locomover por meio de políticas públicas é potencializar a garantia desse direito. A mobilidade urbana bem planejada, conforme a Política Nacional de Mobilidade Urbana (Brasil, 2012), "garante o acesso dos cidadãos às cidades e proporciona qualidade de vida e desenvolvimento econômico" (ob. cit.). Mobilidade urbana, portanto, é estabelecida como um dos quesitos fundamentais para garantir a saúde coletiva por intervir na liberdade e no acesso do cidadão a uma série de atividades importantes para o seu desenvolvimento cotidiano.

Levando em consideração a diversidade de benefícios que o modal cicloviário promove, como a democratização do espaço urbano, a autonomia e a acessibilidade à maioria das classes sociais e faixas etárias (Corrêa et al., 2010), além de impactar pouco no meio ambiente e promover saúde física ao ciclista por ser um modal ativo, é consequente que a bicicleta tem sido "resgatada como um elemento de qualidade de vida urbana, que possibilita a integração e inclusão da população no espaço público" (Florentino, Bertucci, e Iglesias, 2016, p.53). Entretanto, ao mesmo tempo que o transporte motorizado privado foi incentivado no Brasil, o mesmo não pode ser dito do transporte ativo. Na história da política de mobilidade do país até o final da década de 2000 a mobilidade a pé não era entendida como forma de transporte (Vasconcellos, 2016) e pedestres e ciclistas foram atores "invisíveis" no trânsito (ob. cit.), carecendo de políticas e espaços para exercer seus deslocamentos. Se considerado o perfil do ciclista brasileiro (Transporte Ativo e LABMOB-UFRJ, 2018), que pedala 7 dias da semanas, há mais de 5 anos, tem como principal destino o trabalho e que usa e continua a

3 Contribuições: O presente artigo teve por intenção identificar avanços na política de mobilidade por bicicleta na cidade de Campinas, Brasil, por meio da leitura e comparação entre os Planos Diretores atual (2018) e anterior (2006), além de documentos legais complementares referentes ao tema no município. A partir desta identificação é possível notar como o modal cicloviário tem sido priorizado pelo planejamento urbano e qual seu potencial de contribuição e crescimento na solução de diversos problemas urbanos que excedem a mobilidade, como problemas ambientais e de saúde pública. 
usar a bicicleta como meio de transporte porque é mais rápido e prático, é incontestável que a mobilidade por bicicleta no Brasil tem caráter regular e de grande importância para a vivência urbana. Se examinados os principais problemas enfrentados pelo ciclista brasileiro (ob. cit.), que são a falta de segurança no trânsito e a falta de infraestrutura, questões essencialmente de responsabilidade do poder público, surge então a necessidade de investigar que estrutura legal está sendo construída pelo poder público para amparar o modal cicloviário a fim de viabilizar a sua implementação e expansão com adequada integração aos demais modais.

A partir do contexto apresentado, este presente trabalho tem por objetivo identificar avanços na política de mobilidade por bicicleta no município de Campinas pela leitura de seus documentos urbanísticos que abordam a mobilidade urbana. Cabe caracterizar Campinas como uma cidade de grande porte, com população estimada em aproximadamente 1 milhão de habitantes e importante papel no cenário econômico e de produção científica no estado de São Paulo, configurando região metropolitana própria muito próxima à região metropolitana de São Paulo, ao sudeste do Brasil.

\section{Comparação entre os Planos Diretores de Campinas de 2006 e 2018}

A metodologia de estudo sobre os documentos referentes aos Planos Diretores de Campinas foi iniciada por uma leitura geral que buscou identificar a presença de termos relacionados à mobilidade e à bicicleta, seguida de uma leitura comparativa entres os capítulos específicos de mobilidade e transporte dos referentes documentos. A fim de complementar o estudo fez-se uso também dos seguintes documentos que abordam o modal cicloviário no município em questão: "Caderno de acidentalidade no trânsito em Campinas 2017", "Plano Viário do Município de Campinas - Etapa 4: Diagnóstico Síntese dos Resultados do Janeiro de 2018" e "Plano Cicloviário de Campinas 2014-2016".

\section{Identificação de aspectos relevantes da política de mobilidade por bicicleta}

\section{Presença de termos}

Foram identificados os termos "transporte", "mobilidade", "bicicleta" e termos relacionados a "ciclo" (como ciclovia e cicloviário, por exemplo) em ambos os documentos a fim de apontar o grau de importância atribuída à mobilidade por bicicleta no município. No Plano Diretor de Campinas de 2006 foram identificados ao total quarenta termos: "transporte" apareceu trinta e três vezes, "mobilidade" seis vezes, relacionados a "ciclo" uma vez e "bicicleta" nenhuma vez, ao passo que o Plano Diretor de Campinas de 2018 apresentou um total de oitenta e sete termos: "transporte" apareceu quarenta e três vezes, "mobilidade" trinta e quatro vezes, relacionados a "ciclo" nove vezes e "bicicleta" uma vez.

Notou-se um aumento substancial da importância do transporte e da mobilidade dentre as categorias que compõem o Plano Diretor, tanto pelo aumento da presença do termo "transporte", mas principalmente pelo notório crescimento da presença do termo "mobilidade", 
Figura 1. Evolução dos acidentes de trânsito com atropelamento de pedestres no período de 2003 a 2017 no município de Campinas. *No ano de 2017 , em $2 \%(36)$ do total de acidentes não foi possível identificar o tipo de acidente. Fonte: De Caderno de Acidentalidade no Trânsito em Campinas, 2017. de seis vezes para trinta e quatro vezes. O surgimento do termo bicicleta no Plano Diretor de Campinas de 2018, ainda que tímido, acompanhado do aumento de termos relacionados a "ciclo" de uma vez para nove vezes, demonstrou que o modal cicloviário tem sido reconhecido politicamente como um modal a ser desenvolvido.

\section{Comparação entre os capítulos}

O capítulo referente à mobilidade do Plano Diretor de Campinas de 2006 intitula-se "Capítulo IV - Política de Transporte, Trânsito e Mobilidade Urbana" e pertence ao "Título III - das Políticas Públicas". Consta de um artigo ( $49^{\circ}$ artigo) que reuniu objetivos e diretrizes por meio de vinte e cinco incisos. Já o capítulo referente à mobilidade do Plano Diretor de Campinas de 2018 intitula-se "Capítulo VIII - da Mobilidade e Transporte", integrante do título "Título I - do Plano Diretor e da Política de Desenvolvimento do Município", e desdobrou-se em cinco artigos que trouxeram de modo mais evidente o objetivo do capítulo, as diretrizes por meio de dezesseis incisos, além de denotar a necessidade de cumprir o disposto na Lei Federal n. ${ }^{\circ}$ 12587, de 3 de janeiro de 2012, que institui as Diretrizes da Política Nacional de Mobilidade Urbana (Brasil, 2012), e de especificar a hierarquização viária do município. Comparativamente, o documento de 2018 detalhou alguns conceitos previstos no documento de 2006, apresentou um novo conceito que transforma consideravelmente o papel da mobilidade e do transporte para a cidade de Campinas, mas deixou de abordar alguns conceitos pertinentes como a participação popular, a educação e a segurança no trânsito, sendo estes dois últimos pontuados no documento de 2006 como uma de suas diretrizes: "Art. 49 - inciso IV: promover a educação e segurança no trânsito, visando à redução de acidentes" (Campinas, 2006). Se considerados os índices de acidentalidade do município no período de 2006 a 2017 (Campinas, 2018a) apresentados pelo "Caderno de acidentalidade no trânsito em Campinas 2017”, de elaboração

\section{Evolução dos Acidentes Atropelamentos}

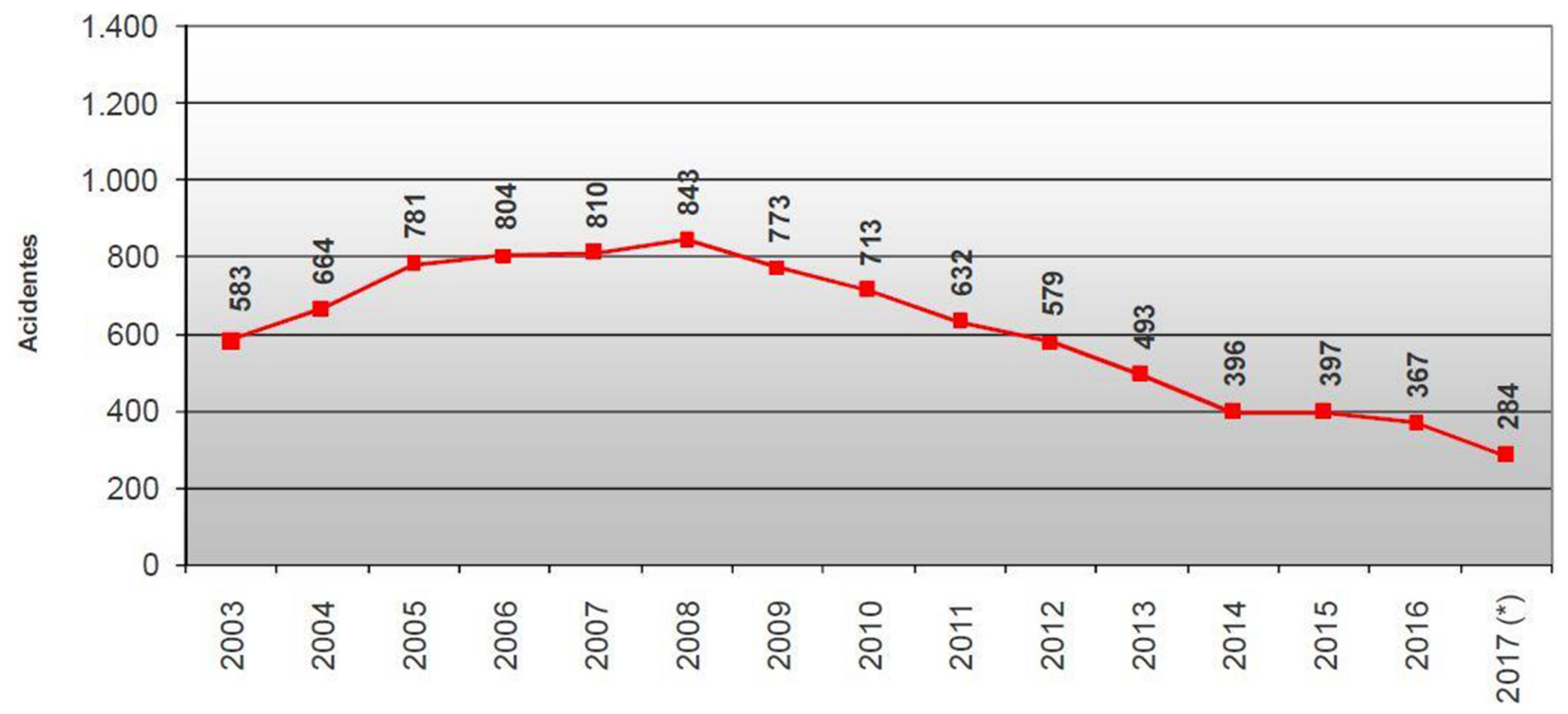




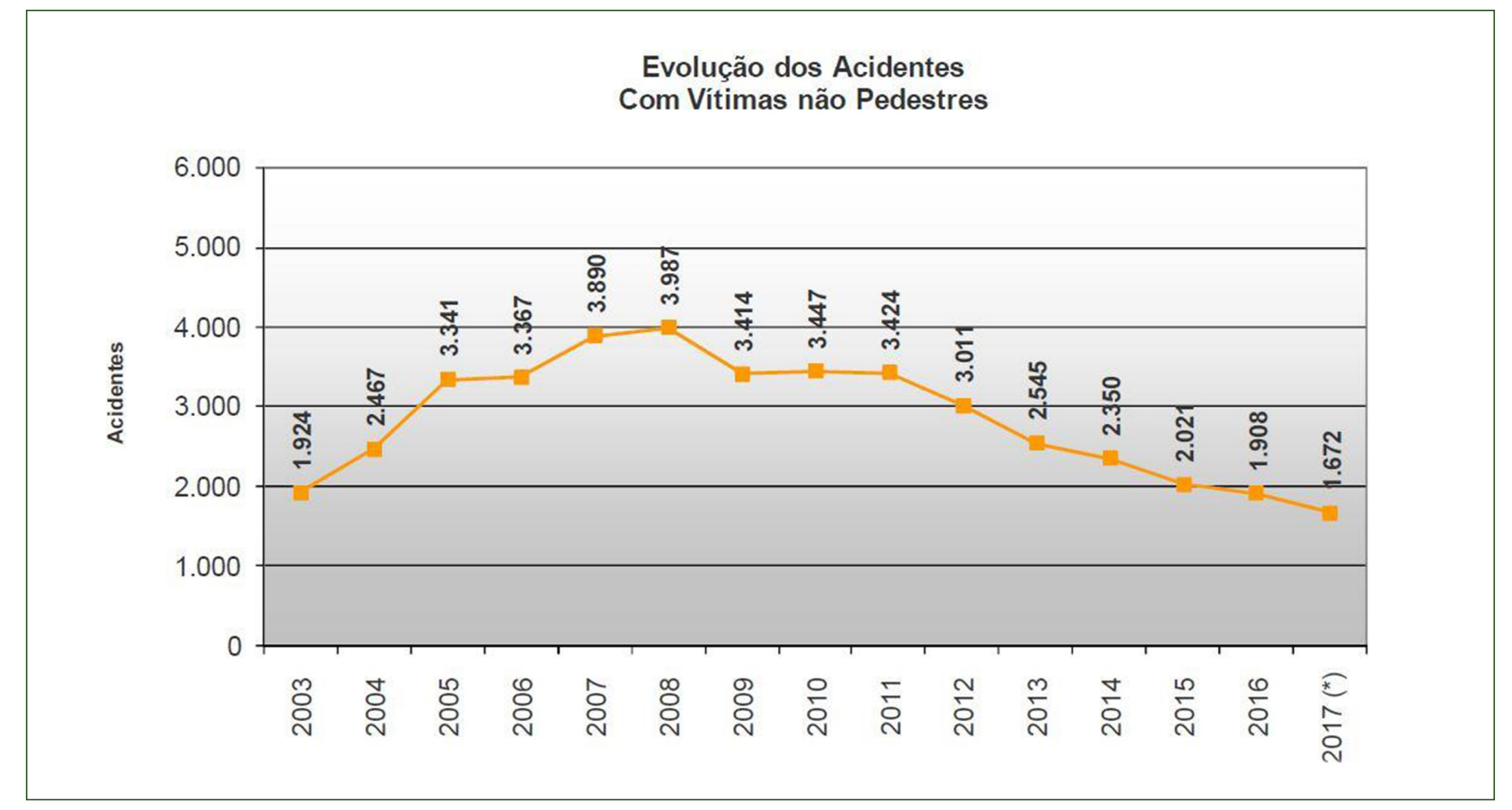

da Empresa Municipal de Desenvolvimento de Campinas (Emdec), a supressão de tais conceitos no documento de 2018 poderia ser explicada pela queda considerável no índice de acidentes de trânsito, tanto de acidentes envolvendo pedestres (atropelamentos) (Figura 1) quanto de vítimas não pedestres (veículos) (Figura 2).

Entretanto, se considerado o índice Comparativo das Vítimas Fatais (Figura 3), encontrou-se em 2017 valor muito próximo ao de 2006, sendo 86 vítimas fatais e 96 vítimas fatais respectivamente, ou seja, inferese que a redução da quantidade de acidentes não implica necessariamente na redução da mortalidade.

Diferentemente dos conceitos de educação e segurança no trânsito, alguns conceitos vieram a ser desenvolvidos no Plano Diretor de 2018. Quanto à hierarquização viária, segundo o disposto no Plano Diretor de Campinas de 2006, "Art. 49 - inciso XVIII - elaborar e implantar novo Plano de Orientação de Tráfego (POT) e elaborar cadastro oficial de hierarquização das vias do Município" (Campinas, 2006), Campinas não detinha informações específicas sobre sua rede viária. O Plano Diretor de Campinas de 2018, entretanto, trouxe detalhes da hierarquização ao categorizar diversas tipologias de vias e atribuir características às mesmas, muito próximas às tipologias dispostas no Código Brasileiro de Trânsito: Via de Trânsito Rápido, Via Arterial I, Via Arterial II, Via Coletora I, Via Coletora II, Via Local, Marginais Municipais e Marginais às infraestruturas (Brasil, 1997). Ciclovias, ciclofaixas e rotas cicláveis foram previstas em função da compatibilidade de velocidade, sendo obrigatória a implantação de ciclovia nas Vias Coletoras I, apontada a possibilidade de haver a implantação de ciclofaixa nas Vias Coletoras II e apontada a indicação da necessidade de implantação de ciclovias e rotas cicláveis nas Vias Arteriais e Coletoras II, a fim de que estas não sejam descontinuadas, a cargo do Poder Público Municipal (Campinas, 2018b).

O Plano Cicloviário, outro conceito desenvolvido, foi somente citado uma vez no documento de 2006: "Art. 49 - inciso XII - elaboração de um Plano Cicloviário Municipal integrado aos outros meios de trans-
Figura 2. Evolução dos acidentes de trânsito com vítimas não pedestres no período de 2003 a 2017 no município de Campinas. ${ }^{*}$ No ano de 2017 , em $2 \%$ (36) do total de acidentes não foi possível identificar o tipo de acidente. Fonte: De Caderno de Acidentalidade no Trânsito em Campinas, 2017. 


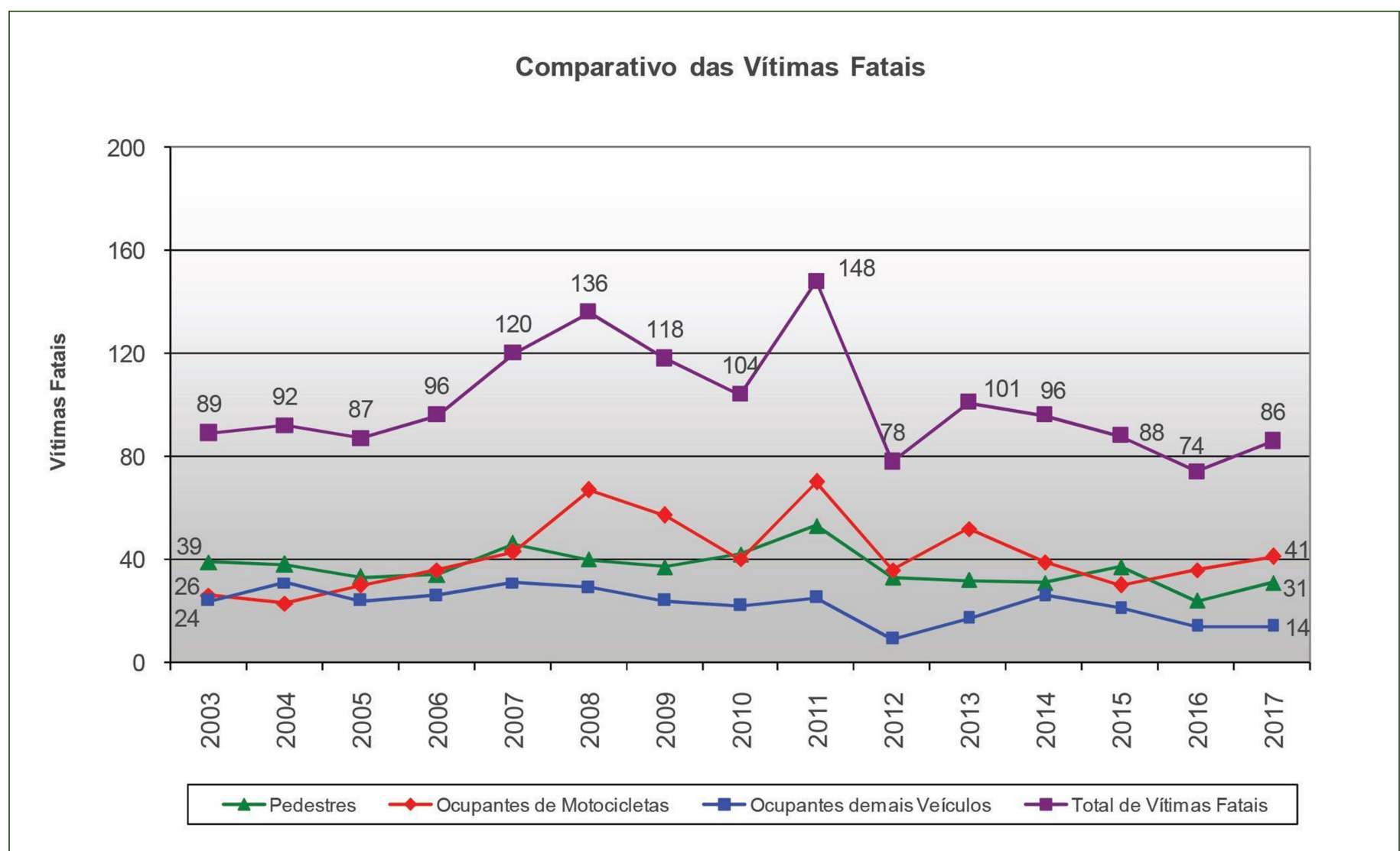

Figura 3. Comparativo das Vítimas Fatais. Fonte: De Caderno de Acidentalidade no Trânsito em Campinas, 2017. porte" (Campinas, 2006). O documento de 2018, entretanto, caracteriza o conceito ao pontuar a necessidade de integração aos outros planos pertinentes à mobilidade e prever a implantação de infraestrutura específica: "Art. 53 - inciso IX - elaboração do Plano Cicloviário de Campinas, associado ao Plano de Mobilidade e ao Plano Viário, prevendo a implantação de ciclovias, bicicletários e sistemas de apoio à ciclomobilidade" (Campinas, 2018b). Evidencia-se também o destaque conferido ao transporte não motorizado: "Art.53 - inciso VII - desenvolvimento de políticas públicas que promovam a qualificação das calçadas e espaços de circulação de pedestres com segurança e conforto, priorizando o pedestre, o transporte público e a mobilidade não motorizada, frente aos modos privados motorizados" (ob. cit.).

A principal alteração identificada de um documento ao outro foi a percepção da necessidade de se elaborar e planejar a mobilidade e o transporte conjuntamente aos demais aspectos do Plano Diretor e não posteriormente, percepção esta apresentada pela introdução do conceito de Desenvolvimento Orientado pelo Transporte (DOT). A promoção de ações de planejamento urbano e de mobilidade devem ocorrer de forma integrada, onde a oferta de transporte público deve ser compatível com o ordenamento territorial, como posto pelo inciso I do artigo 53 (Campinas, 2018b). Deste modo, apreende-se que a mobilidade passou a ter um papel também de direcionar e conformar a expansão urbana pela provisão de infraestrutura e não mais somente a de suprir necessidades estabelecidas posteriormente à expansão.

\section{Conceito de Desenvolvimento Orientado pelo Transporte}

Segundo o documento "Plano Viário do Município de Campinas Etapa 4: Diagnóstico Síntese dos Resultados" de Janeiro de 2018, que foi parte do desenvolvimento do Plano Viário previsto pelo Plano Di- 
retor de Campinas de 2018, o conceito de Desenvolvimento Orientado pelo Transporte apresentou como objetivo maximizar o acesso aos sistemas de transporte coletivo, por meio da densificação das áreas lindeiras aos eixos de transporte, além de transformar as áreas no entorno das estações de acesso em áreas compactas (Campinas, 2018c). O documento trouxe também o entendimento de que os Planos de Transporte não devem apenas procurar resoluções para atender a demanda existente ou projetada, mas devem, simultaneamente, observar as dinâmicas territoriais, pois apontou que a conformação do uso do solo é um dos principais fatores geradores de demanda. Assim, os Planos de Transporte devem ser elaborados como estruturadores do território integrados com as políticas setoriais urbanas, considerando como principais atributos os seguintes conceitos para a análise (Campinas, 2018c):

- Compactar: a ligação entre atividades realizadas mais proximamente as outras consome menos tempo e energia;

- Densificar: intensificar o uso do solo verticalmente permite compactar e combinar de forma mais eficiente diversas atividades;

- Transportar: a densificação deve começar nos corredores de transporte de massa, essencial para garantir uma cidade acessível a todos;

- Conectar: a oferta de distintos modais por meio de uma rede coesa de vias, rua de pedestres e ciclovias, além do transporte público de massa, promovem deslocamentos mais diretos e eficientes;

- Misturar: o uso diversificado do solo torna os bairros mais vivos e resulta em trajetos mais curtos;

- Usar a bicicleta: é uma opção de modal eficiente e conveniente, aumentando o acesso das pessoas a uma área maior, além de colaborar com a cobertura do transporte de massa;

- Promover mudanças: além da maior oferta de transporte aos cidadãos, também são necessárias políticas de controle de tráfego e de estacionamento como modo de reduzir sensivelmente o uso de veículos motorizados particulares;

- Andar a pé: promover a segurança que permita a mobilidade a pé traduz-se em ruas mais movimentadas e vibrantes, o que é fundamental para uma mobilidade bem sucedida nas cidades.

Os oito conceitos, acima apresentados pelo documento, foram mensurados por meio de uma metodologia de análise que resultou em um diagnóstico, aplicada a cada uma das dezessete Áreas de Planejamento e Gestão (APGs) do município com o intuito de classificá-las como "inadequada", "adequada" ou "ideal" por meio de uma pontuação resultante da soma de uma série de itens distribuídos e ponderados nas seguintes oito categorias, baseadas nos princípios do DOT: "caminhar", "pedalar", "conectar", "usar transporte público", "misturar", "adensar", "compactar" e "mudar".

\section{Avaliação DOT - Pedalar}

Como modo de exemplificar a aplicação da metodologia estabelecida pela avaliação DOT o documento "Plano Viário do Município de Campinas - Etapa 4: Diagnóstico Síntese dos Resultados" apresentou um estudo na APG Eixo Barão Geraldo - Trecho 1. Os critérios foram ponderados de três modos (Quadro 1): peso 0 para a avaliação "inadequado", peso 0,7 para a avaliação "adequado" e peso 1 para a avaliação 
Quadro 1. Exemplo de análise - Eixo Barão Geraldo, Trecho BG 1, Avaliação DOT. Destaca-se a categoria 2, Pedalar. Fonte: De Plano Viário do Município de Campinas - Etapa 4: Diagnóstico Síntese dos Resultados, 2018 "ideal". Os critérios relativos à categoria "Pedalar" foram definidos em seis itens e abordaram unicamente critérios relacionados à Infraestrutura Cicloviária. São eles, com os respectivos pesos em relação ao total possível: Presença de ciclovia/ciclofaixa (peso 3 de 10); Rede cicloviária completa e articulada (peso 2 de 10); Presença de paraciclos/bicicletários (peso 2 de 10); Acesso da bicicleta nos terminais de ônibus (peso 1 de 10); Oferta de sistema de bicicleta compartilhada (peso 1 de 10); e Velocidade regulamentada do trânsito geral em locais de implantação de infraestrutura cicloviária (peso 1 de 10).

\begin{tabular}{|c|c|c|c|}
\hline A & Infraestrutura Cicloviária & 10 & 1.0 \\
\hline 2.1 & Presença de ciclovia / ciclofaixa & 3 & 0.0 \\
\hline 2.2 & Rede cicloviária completa e articulada & 2 & 0.0 \\
\hline 2.3 & Presença de paraciclos / bicicletários & 2 & 0.0 \\
\hline 2.4 & Acesso da bicicleta nos terminais de ônibus & 1 & 0.0 \\
\hline 2.5 & Oferta de sistema de bicicleta compartilhada & 1 & 0.0 \\
\hline 2.6 & $\begin{array}{l}\text { Velocidades regulamentada do trânsito geral em locais } \\
\text { de implantação de infraestrutura cicloviária }\end{array}$ & 1 & 1.0 \\
\hline
\end{tabular}

Figura 4. Avaliação Geral das APGs: DOT- PEDALAR. Fonte: De Plano Viário do Município de Campinas - Etapa 4: Diagnóstico Síntese dos Resultados, 2018.
O exemplo em questão apresentou um total de pontuação de 1 de 10, demonstrando a quase inexistência de infraestrutura que atenda ao princípio "Pedalar" do Desenvolvimento Orientado pelo Transporte na APG em questão, pois o único item a receber pontuação foi o item 2.6 que trata da regulamentação geral da velocidade em vias de implantação de infraestrutura cicloviária. Quando observada a avaliação geral do município, foi identificado que o território era predominantemente "inadequado" e inexistiam áreas ideais para pedalar em Campinas (Figura 4).

\section{A EMDEC}
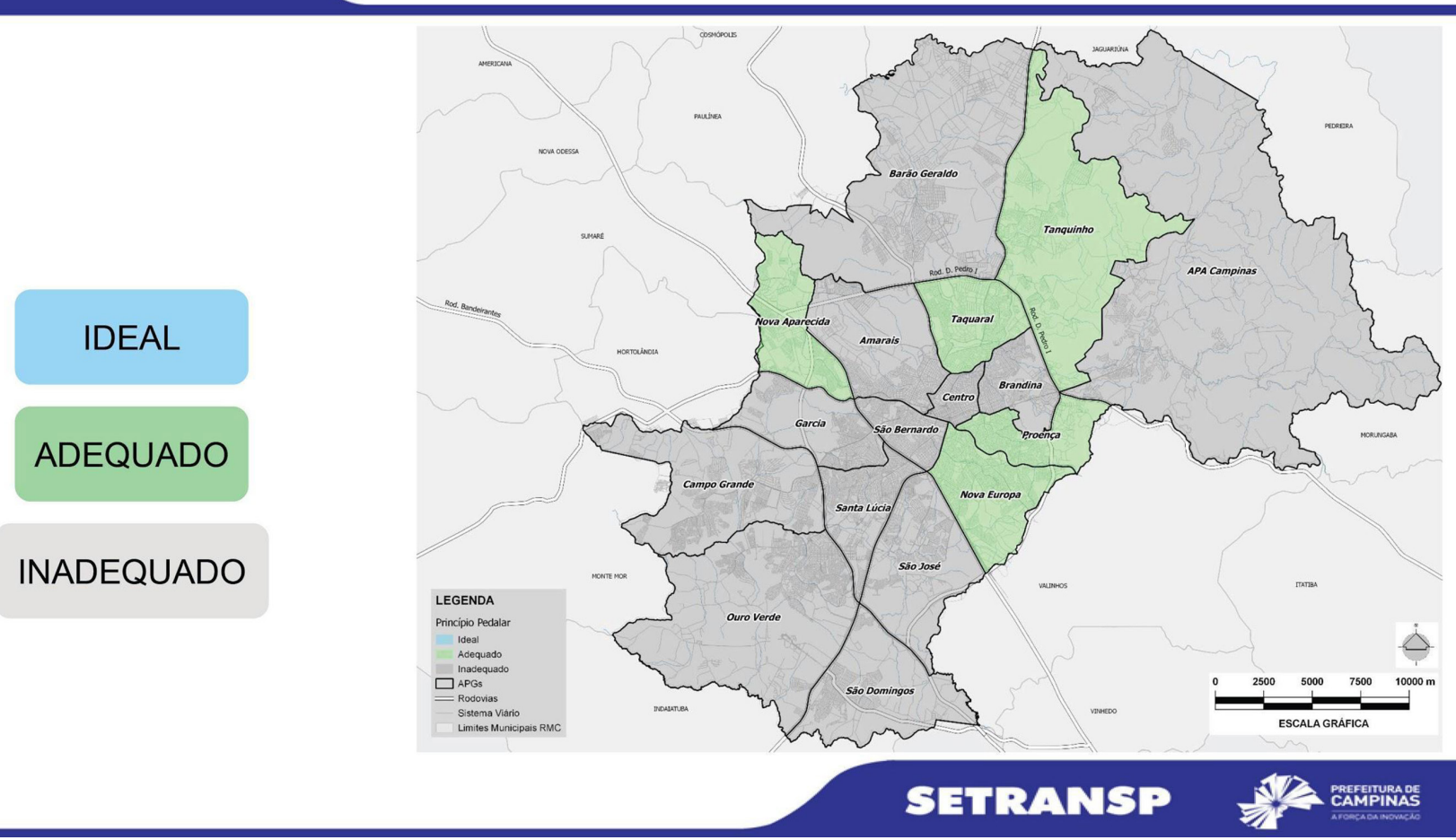
A análise realizada pelo Diagnóstico do Plano Viário na categoria Pedalar foi reiterada pelo "Plano Cicloviário de Campinas 2014-2016". Este Plano Cicloviário, pontuado em ambos os Planos Diretores, apresentou inicialmente um resumo quantitativo da extensão total de Ciclovias e Rotas Cicláveis existentes no município quando foi elaborado assim como as extensões previstas para as quatro fases de implementação do Plano Cicloviário. As Premissas Básicas do mesmo são essencialmente técnicas, trazendo definições de termos, viés de implantação e a ressalva da necessidade de integração por outros projetos de transporte como o BRT (Bus Rapid Transit). Os mapas que apresentaram as diferentes fases de implementação são pouco precisos (Figura 5), com imagens de satélite de baixa definição e perspectivadas, o que distorce a escala das ciclovias e rotas cicláveis apresentadas, além da ausência de apresentação das principais vias do município que determinam a estrutura da cidade.

\section{A. EMDEC \\ PLANO CICLOVIÁRIO DE CAMPINAS}

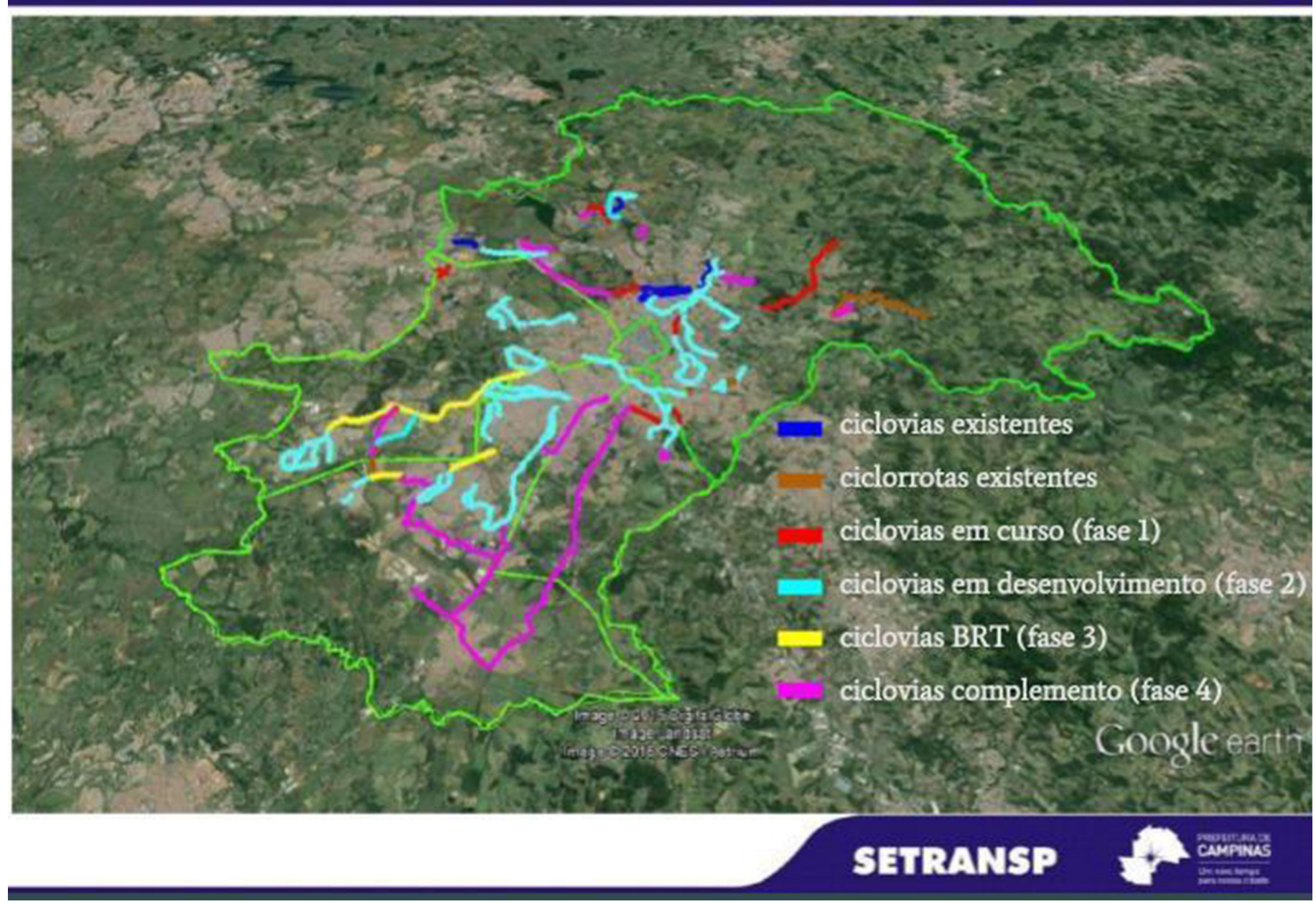

\section{Considerações finais}

Os resultados identificados indicam de forma geral avanços na política de mobilidade por bicicleta na cidade de Campinas, porém com diversas ressalvas a serem apontadas. As considerações iniciam-se pela verificação de que os índices de fatalidade por acidentes de trânsito no município não foram reduzidos significativamente, apontando, portanto,
Figura 5. Mapa resumindo as Ciclovias e Rotas Cicláveis existentes e as quatro fases elaboradas no Plano Cicloviário de Campinas 2014-2016. Fonte: Plano Cicloviário de Campinas - 2014-2016, 2015 com elaboração própria da legenda sobre a imagem. 
que a educação e a segurança no trânsito devem observar, para além da quantidade, a qualidade do acidente e adaptar as ações políticas de prevenção não somente para a redução da acidentalidade como também orientá-las em função da tipologia do acidente. Logo, para que seja possível a manutenção dos baixos índices de acidentalidade, quando estes forem atingidos, é necessário ainda manter e explicitar os conceitos de educação e segurança no trânsito nas renovações dos Planos Diretores. A partir de uma definição qualificada é possível um comprometimento mais claro por parte do poder público, assim como o fornecimento de subsídio para a população se posicionar perante tais conceitos. A indefinição acaba por dificultar não só o entendimento do Plano Diretor como também restringir ações de monitoramento pela sociedade das ações tomadas pelo poder público, uma vez que esta não dispõe de clara referência das metas de mobilidade a serem alcançadas pelo município.

Um exemplo de indefinição, que caracterizou a hierarquização viária no documento de 2006, assinalou que Campinas até então não possuía uma clareza da própria rede viária, o que indicou a necessidade de realizar tal levantamento para possibilitar um planejamento preciso e coerente à realidade, o que foi desenvolvido para o Plano Diretor seguinte de 2018. Entretanto, a indefinição também atribuída ao Plano Cicloviário em 2006 e denunciada pelo próprio artigo indefinido "um" que o precedia, não recebeu a mesma especificidade necessária e foi pouco desenvolvida. As informações complementares apresentadas pelo Plano Viário foram essencialmente de infraestrutura, como ciclovias, ciclofaixas, paraciclos e bicicletários, oferta de sistema de bicicleta compartilhada e compatibilização com a velocidade da via, apresentando nenhuma forma de avaliação que envolva o ciclista e suas necessidades, o que vai ao encontro com a ausência do conceito de participação popular no capítulo referente à mobilidade do Plano Diretor de 2018.

A necessidade da institucionalização vertical para o crescimento do uso da bicicleta como meio de transporte nas cidades brasileiras é clara para os ciclistas, pois é possível identificar duas visões dentre o movimento cicloativista no país, "uma visão mais autonomista do movimento, e outra visão mais institucionalizada cujo objetivo é a construção de uma política pública cicloviária de estado, e não apenas referente a um governo" (Filho e Junior, 2017, p.35). Ainda que a premissa de participação social nos processos de construção de políticas de mobilidade urbana seja clara para a população interessada, muitas vezes não é contemplada nas ações do poder público. Sinais que denunciam a distância entre a teoria da legislação de mobilidade em Campinas e sua implementação podem ser ilustrados pelo processo licitatório do transporte público da Prefeitura de Campinas e da Emdec. O Ministério Público observou falta de efetiva participação popular na elaboração do edital da licitação e a Justiça do Estado de São Paulo determinou que os órgãos responsáveis providenciassem dentro de um determinado prazo a realização de consultas populares e audiências públicas (G1-Campinas e Região, 2019), a fim de que a população fosse devidamente informada de suas características e pudesse manifestar-se sobre a mesma. Este processo demonstrou que a atuação da sociedade, por meio de uma organização não governamental junto a um instituto que denunciaram apontamentos questionáveis do edital da licitação ao Ministério Público (Câmara Municipal de Campinas, 2019), foi eficiente no monitoramento da implementação de mudanças na mobilidade do município, demonstrando o potencial de bons resultados se a mesma 
também fosse convidada a participar mais ativamente na elaboração de tais mudanças.

Ainda que seja necessário desenvolver muitos esforços no âmbito da participação popular no processo de elaboração da legislação de mobilidade e transporte na cidade, a mudança no modo de planejá-los que o Plano Diretor de Campinas de 2018 trouxe pela inserção do conceito DOT é de grande avanço. Ao integrar ao planejamento e desenvolvimento urbano, o documento associa provisão de infraestrutura à expansão urbana, intensificando o controle sobre a mesma. Entretanto, considerando o destaque conferido pelo conceito DOT à necessidade de se investir em modais não motorizados, como caminhar e pedalar, somado aos índices de acidentalidade apresentados, é preocupante que o Plano Diretor de Campinas de 2018 não tenha abordado explicitamente a necessidade de se desenvolver políticas e ações no que concernem à educação e segurança no trânsito, levantando-se o questionamento sobre a compatibilidade entre a fragilidade dos usuários de tais modais e a ausência de campanhas e ações que garantam a segura expansão do mesmos.

Por fim, os documentos complementares aos Planos Diretores que abordam o modal cicloviário no município de Campinas possibilitam notar que há avanços na política de mobilidade com enfoque à bicicleta. O desenvolvimento de critérios para a avaliação DOT, especificamente para o "Pedalar", assim como a elaboração do "Plano Cicloviário de Campinas 2014-2016”, permitem iniciar uma estruturação legal que ampare o crescimento deste modal alternativo ao dominante no país, o individual e motorizado. A leitura profunda de tais documentos, porém, esclareceu seu caráter ainda distante do usuário, com prevalência de uma abordagem técnica que ainda que seja primordial, não contempla a complexidade dos conflitos resultantes da integração (ou falta de) entre os diversos modais de transporte na cidade. É necessário incluir na elaboração do Plano Cicloviário do município conceitos que contemplem as especificidades do modal cicloviário, como sensação de segurança, acessibilidade física e financeira, seu impacto positivo na saúde do usuário, seu baixo impacto ambiental, dentre outras, especificidades estas que conformam, juntamente à provisão de infraestrutura, razões atraentes para a escolha da bicicleta como principal modo de deslocamento nas cidades, potencializando sua expansão e uma aproximação com o planejamento urbano para uma cidade saudável. 
Brasil. Presidência da República (1997). Código de Trânsito Brasileiro (Lei n. ${ }^{\circ}$ 9503, de 23 de setembro). Brasília: Presidência da República. Recuperado em 16 de julho de 2019, de: http:/ / www.planalto.gov. br/ccivil_03/leis/19503.htm.

Brasil. Assembleia Nacional Constituinte (1988). Constituição da República Federativa do Brasil de 1988. Brasília: Presidência da República. Recuperado em 06 de setembro de 2018 de: http:/ / www.planalto.gov. br/ccivil_03/constituicao/constituicao.htm.

Brasil. Câmara dos Deputados (2012). Política Nacional de Mobilidade Urbana (Lei n. ${ }^{\circ} 12587$, de 3 de janeiro). Brasília: Presidência da República. Recuperado em 01 de abril de 2019 de: http:/ / www.planalto.gov. br/ccivil_03/_ato2011-2014/2012/lei/112587.htm.

Câmara Municipal de Campinas (2019, 09 de dezembro). Comissão Especial de Estudos da Licitação de Ônibus recebe responsáveis pela denúncia de dúvidas do edital ao Ministério Público. Câmara Municipal de Campinas. Recuperado em 15 de janeiro de 2020 de: https://www.campinas.sp.leg. br/comunicacao/noticias/2019/dezembro/comissao-especial-de-estudos-da-licitacao-de-onibus-recebe-responsaveis-pela-denuncia-de-duvidas-do-editalao-ministerio-publico.

César, Yuriê Baptista (2010). A garantia do direito à cidade através do incentivo ao uso da bicicleta nos deslocamentos urbanos (Trabalho de Conclusão de Curso). Brasília: Instituto de Ciências Humanas (UnB), . Recuperado em 19 de maio de 2019 de: https:/ /www. mobilize.org.br/midias/pesquisas/a-garantia-do-direito-a-cidade.pdf.

Corrêa, Ricardo; Cunha, Kamyla Borges da; e Boareto, Renato (2010). A bicicleta e as cidades: como inserir a bicicleta na política de mobilidade urbana. São Paulo: Instituto de Energia e Meio Ambiente. Recuperado em 19 de maio de 2019 de: http:/ / energiaeambiente.org.br/produto/a-bicicleta-e-as-cidades.

Filho, Osmar Coelho e Junior, Nilo Luiz Saccaro (2017). Cidades Cicláveis: avanços e desafios das políticas cicloviárias no Brasil. Brasília: Instituto de Pesquisa Econômica Aplicada. Recuperado em 25 de fevereiro de 2020 de: http:/ / repositorio.ipea.gov.br/ handle/11058/7521.

Florentino, Renata; Bertucci, Jonas; e Iglesias, Fabio (2016). Os caminhos dos ciclistas em Brasília/DF. Em Andrade, Victor, Rodrigues, Juciano, Lobo, Zé (org.), Mobilidade por Bicicleta no Brasil (pp. 51-75). Rio de Janeiro: PROURB/UFRJ. Recuperado em 11 de abril de 2019 de: http:/ / transporteativo.org. $\mathrm{br} / \mathrm{ta} /$ ?page_id=9083.

G1 Campinas e Região (2019, 04 de novembro). Justiça suspende nova licitação do transporte de Cam- pinas e determina consultas populares. G1 Campinas e Região. Recuperado em 13 de janeiro de 2020 de: https://g1.globo.com/sp/campinas-regiao/noticia/2019/11/04/justica-suspende-nova-licitacaodo-transporte-de-campinas-e-determina-consultaspopulares.ghtml.

Instituto de Pesquisa Econômica Aplicada (2013). Tarifação e financiamento do transporte público urbano. Nota Técnica. Brasília: Instituto de Pesquisa Econômica Aplicada. Recuperado em 23 de março de 2020 de: http:/ / repositorio.ipea.gov.br/handle/11058/1365.

Prefeitura Municipal de Campinas (2018a). Caderno de acidentalidade no trânsito em Campinas 2017. Campinas: Secretaria de Transportes e Empresa Municipal de Desenvolvimento de Campinas. Recuperado em 10 de outubro de 2019, de: http:/ / www.emdec. com.br/eficiente/repositorio/EMDEC_documentos/17789.pdf.

Prefeitura Municipal de Campinas (2006). Lei Complementar $n .^{\circ} 15$, de 27 de dezembro de 2006, dispõe sobre o Plano Diretor do Município de Campinas (revogada pela Lei Complementar n. ${ }^{\circ} 189$, de 08 de janeiro de 2018). Campinas: Câmara Municipal. Recuperado em 16 de outubro de 2019, de: https:/ / leismunicipais.com.br/a/sp/c/campinas/leicomplementar/2006/1/15/lei-complementar-n15-2006-dispoe-sobre-o-plano-diretor-do-municipiode-campinas.

Prefeitura Municipal de Campinas (2018b, 09 de janeiro). Lei Complementar $n .^{\circ} 189$, de 08 de janeiro de 2018, dispõe sobre o Plano Diretor do Município de Campinas. Campinas: Câmara Municipal. Recuperado em 24 de outubro de 2019, de: http:/ / suplementos.campinas.sp.gov.br/admin/download/suplemento_2018-01-09_cod473_1.pdf.

Prefeitura Municipal de Campinas (2015). Plano Cicloviário de Campinas 2014-2016. Campinas: Secretaria de Transportes e Empresa Municipal de Desenvolvimento de Campinas. Recuperado em 10 de outubro de 2019, de: http:/ /www.emdec.com.br/eficiente/repositorio/1SiteNovo/Transito/18787.pdf.

Prefeitura Municipal de Campinas (2018c). Plano Viário do Município de Campinas-Etapa 4: Diagnóstico síntese dos resultados. Campinas: Secretaria de Transportes e Empresa Municipal de Desenvolvimento de Campinas. Recuperado em 10 de outubro de 2019, de: http:/ / www.emdec.com.br/eficiente/repositori o/1SiteNovo/2017/16433.pdf.

Silva, Claudio Oliveira da (2009). Cidades concebidas para o automóvel: mobilidade urbana nos planos diretores posteriores ao Estatuto da Cidade (Dissertação de Mestrado), Faculdade de Arquitetura e Urbais- 
mo (UnB), Brasília. Recuperado em 19 de maio de 2019, de: https:/ / repositorio.unb.br/handle/10482/3936.

Transporte Ativo e LABMOB-UFRJ (2018). Pesquisa Perfil do Ciclista 2018. Rio de Janeiro: Transporte Ativo e LABMOB-UFRJ. Recuperado em 29 de abril de 2019, de: http:/ / ta.org.br/perfil/ciclista18.pdf.

Vasconcellos, Eduardo Alcântara de (2016). Mobilidade Cotidiana, Segregação Urbana e Exclusão. Em
Balbim, Renato, Krause, Cleandro, Linke e Clarisse Cunha (org.), Cidade e Movimento: mobilidades e interações no desenvolvimento urbano (pp. 57-79). Brasília: Ipea/ITDP. [ISBN: 978-85-7811-284-4]. Recuperado em 09 de março de 2020, de: https:/ / www.ipea.gov.br/portal/index.php?option=com_ content\&view=article\&id=28489.

Shue Lang Lin, Pamela; y Girotti Sperandio, Ana Maria (2020). Avanços na política de mobilidade por bicicleta em Campinas: comparação entre os Planos Diretores de 2006 e de 2018. Hábitat y Sociedad, 13, 251-263.

<http://dx.doi.org/10.12795/HabitatySociedad.2020.i13.14>

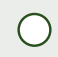




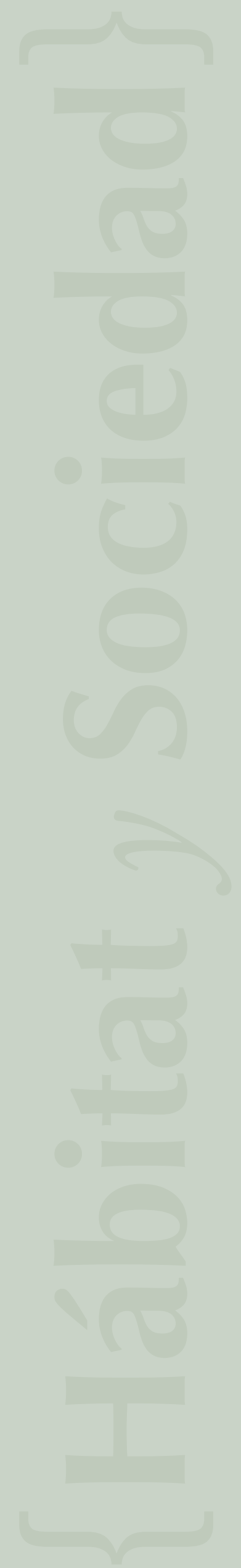

